\title{
The relationship between Graves' ophthalmopathy and dry eye syndrome
}

\author{
This article was published in the following Dove Press journal: \\ Clinical Ophthalmology \\ 31 December 2014 \\ Number of times this article has been viewed
}

\author{
Jessica H Selter ${ }^{1}$ \\ Anisa I Gire ${ }^{2}$ \\ Shameema Sikder ${ }^{2}$ \\ Johns Hopkins School of Medicine, \\ ${ }^{2}$ Wilmer Ophthalmological Institute, \\ Johns Hopkins University School \\ of Medicine, Baltimore, MD, USA
}

\begin{abstract}
Background: A complex relationship between Graves' ophthalmopathy (GO) and dry eye syndrome exists. New research brings more insight into the association between these two diseases.

Methods: A review of the literature was conducted using the query terms "Graves' Ophthalmopathy", "Thyroid Eye Disease", and "Dry Eye" in MedLine (PubMed) and Scopus. A total of 55 papers were reviewed. Case reports were excluded.

Conclusion: This review paper shows the close relationship between dry eye syndrome and GO. The underlying mechanisms behind their association suggest mechanical impairment of orbital muscles and immune-mediated lacrimal gland dysfunction as the causes of dry eye in GO patients. However, there are a variety of treatment options available for patients with GO with signs of dry eye, which help combat this issue.
\end{abstract}

Keywords: Graves' ophthalmopathy, dry eye, thyroid eye disease, ocular inflammation

\section{Introduction}

Dry eye syndrome (DES) is defined by an abnormal tear film that results in changes to the ocular surface, which can lead to ocular discomfort. ${ }^{1,2}$ Its symptoms may include blurred vision, burning, itchiness, redness, or grittiness in the eye, and sensitivity to light. ${ }^{1-3}$ DES is a common disease and is increasingly prevalent among people with autoimmune disease and thyroid disorders, in postmenopausal women, and in the elderly. ${ }^{1-3}$

Graves' ophthalmopathy (GO) is a disease often associated with DES that is the most frequent cause of ocular discomfort in GO patients. ${ }^{4} \mathrm{GO}$, also known as thyroidassociated orbitopathy, thyroid eye disease, or Graves' orbitopathy, is an autoimmune disease in which autoantibodies to the thyroid-stimulating hormone receptor lead to the excess production of thyroid hormone and induce an inflammatory response in the orbital tissues. ${ }^{5}$ GO occurs in about half of Graves' disease (GD) cases; ${ }^{6,7}$ onset is usually within 12-18 months of the systemic GD symptoms with an active phase that is followed by spontaneous remission. Unfortunately, in some patients, the active phase can later return. ${ }^{8}$ The estimated occurrence of GO in women is 16 cases per 100,000 people per year, and in men, 3 cases per 100,000 people per year. ${ }^{9,10}$ GO is most often seen with concomitant hyperthyroidism (80\%); however, it can also be seen in hypothyroid and euthyroid states. ${ }^{11}$

In $\mathrm{GO}$, it is hypothesized that there is a cross-reactivity against an antigen that is in both thyroid and orbital tissues, which leads to an autoimmune orbital reaction. ${ }^{7,12}$ T lymphocytes invade into orbital tissue and musculature in response to a similar antigen found in thyroid tissue. ${ }^{5}$ This inflammatory process often leads to glycosaminoglycan deposition, fibrosis of extraocular muscles, and adipogenesis in the area around the
Correspondence: Shameema Sikder Wilmer Eye Institute, 7315 Wisconsin Ave, Suite 6I0-W, Bethesda, MD 20910, USA

Tel +I 240482 I I 00

Fax +I 240482 II05

Email ssikder I@jhmi.edu 
orbit. ${ }^{13,14}$ Clinically, this autoimmune response can result in the classic presentation of eyelid retraction in $80 \%-90 \%$ of patients, lagophthalmos, exophthalmos, restrictive myopathy, and diplopia. ${ }^{9}$ These clinical manifestations can lead to problems with vision, ocular motility, and physical disfigurement. Due to these problems, particularly dry eye symptoms, the quality of life of people with GO is often diminished. ${ }^{15}$

Although the association between DES and GO has long been known, recent research has increased our understanding of the mechanism behind this relationship with potential treatments for these concurrent diseases. This paper reviews current knowledge about the relationship between GO and DES.

\section{Discussion}

\section{Epidemiology}

DES is one of the most common ophthalmologic complaints, affecting millions of people around the world and is a significant health care concern. ${ }^{16}$ Severe DES can have as large an impact on quality of life as end-stage renal disease. ${ }^{17}$ Largescale population-based studies suggest that the prevalence of DES is approximately $14 \%-15 \%$ of the population aged 50 and older. ${ }^{3,16,18}$ DES patients are often elderly and have some other type of systemic disease or comorbid medical condition. ${ }^{19}$

Nonetheless, DES is especially common in patients who have concurrent thyroid disease. Many studies around the world demonstrate that there is an increased risk of having DES in patients who have thyroid disease. ${ }^{18,20,21}$ Studies that specifically examine GO show that an estimated 65\%-85\% of GO patients also have dry eye symptoms. ${ }^{10,22-24}$

\section{Ocular surface changes}

Clinical researchers have recognized the importance of accurate assessment of ocular surface health in GO, and the major GO classification schemes include either qualitative or quantitative ocular surface assessments. ${ }^{25-27}$ These classification systems include the NOSPECS, Clinical Activity Score, and the VISA system, which all utilize some aspect of ocular surface damage in GO to help determine disease severity in patients (Table 1). ${ }^{25-27}$ Patients with GO and DES often have significant ocular surface damage compared to healthy eyes. ${ }^{28}$ Patients with GO and dry eye have significantly lower Schirmer tests $(14.4 \pm 8.34 \mathrm{~mm})$ compared with normal controls $(24.9 \pm 3.57 \mathrm{~mm})$, suggesting inadequate

Table I Classification systems used for Graves' ophthalmopathy

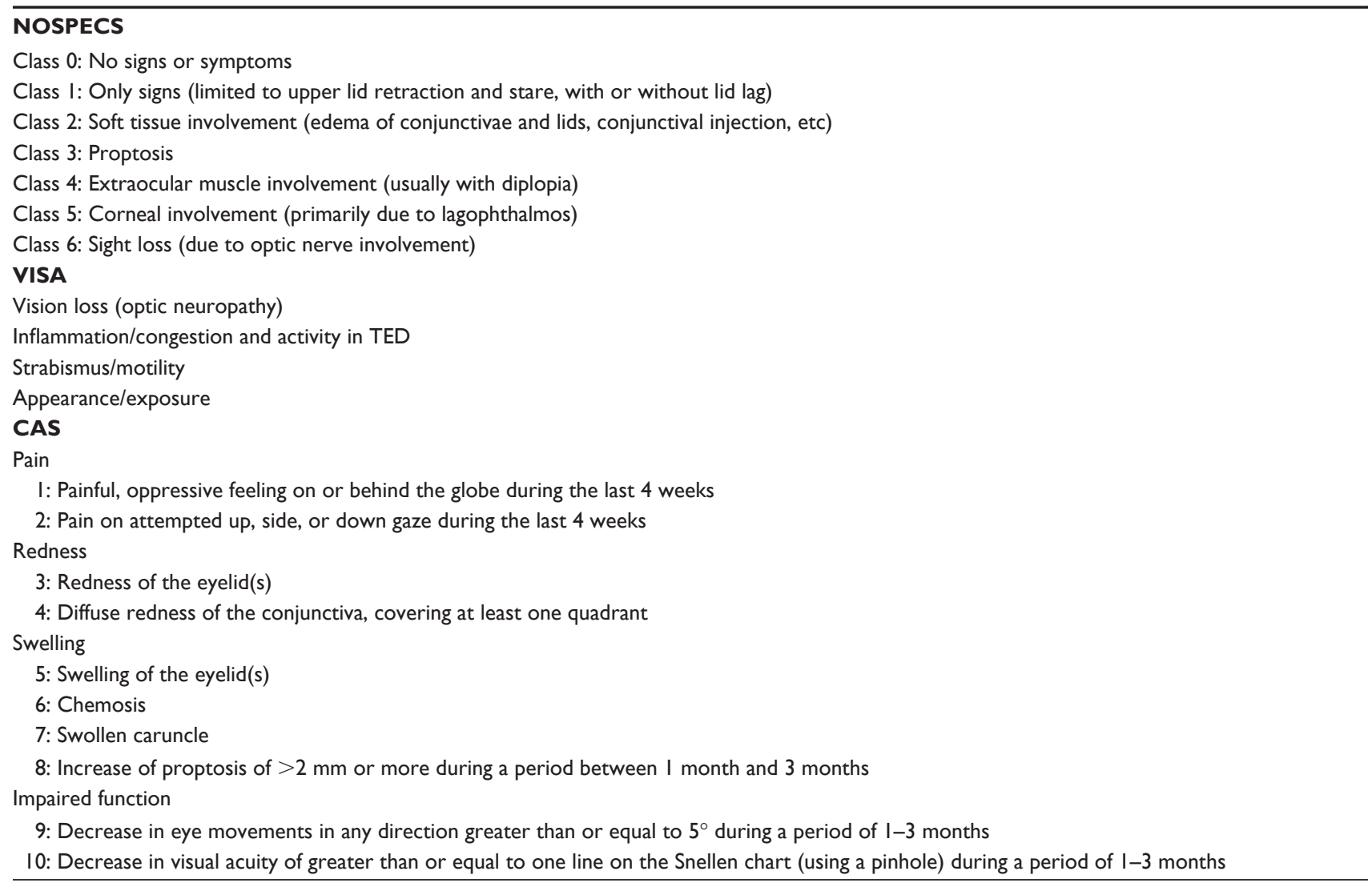

Notes: For each of the signs present, one point is given. The sum of these points defines the activity score.

Abbreviations: TED, thyroid eye disease; CAS, Clinical Activity Score. 
tear production. ${ }^{4}$ The tear breakup time in GO patients with dry eye $(5.84 \pm 3.31 \mathrm{~s})$ is significantly lower than controls $(11.4 \pm 3.75 \mathrm{~s})$, suggesting an unstable tear film. ${ }^{22,29,30} \mathrm{Mul}-$ tiple studies demonstrate that the tear film osmolarity in GO patients is significantly higher than controls, as determined by auto-osmometry $(290.80 \pm 13.58 \mathrm{mOsm}$ in control and $340.38 \pm 18.74 \mathrm{mOsm}$ in the patients). ${ }^{28,31}$ The ocular surface disease index (OSDI) is an assessment tool used by ophthalmologists to determine the symptoms of dry eye in their patients; GO patients are noted to have an increased OSDI compared with controls. ${ }^{29}$

Rose Bengal and fluorescein staining show significantly more ocular damage in patients with GO and dry eye compared with controls. In one study, impression cytology in GO and dry eye patients showed a reduced goblet cell density, a decreased nuclear/cytoplasmic ratio, and excessive desquamation in conjunctival cells compared with normal controls. ${ }^{29}$ Another study using impression cytology finds epithelial dystrophy with cell polymorphism and epithelial keratinization with local leukocyte infiltration in GO patients' eyes. ${ }^{24}$ When examining patients' eyes with confocal microscopy, there is a significant reduction in surface epithelial cells in the cornea of patients with GO and dry eye compared with controls $\left(1,011.36 \pm 199.36\right.$ cell $/ \mathrm{mm}^{2}$ in patients and $1,517.15 \pm 130.65$ cells $/ \mathrm{mm}^{2}$ in controls). There is also an increased stromal cell density $\left(1,215.81 \pm 88.71\right.$ cells $/ \mathrm{mm}^{2}$ in patients and $971.15 \pm 103.56$ cells $/ \mathrm{mm}^{2}$ in controls) with increased hyperreactive activated keratocytes $(6.04 \pm 2.93 \mathrm{cells} /$ frame in patients and $0.42 \pm 0.73$ cells/frame in controls), suggesting corneal inflammation in these patients. ${ }^{8}$ Patients with early signs of GO also have reduced corneal sensitivity. ${ }^{23}$ GO patients, when examined using confocal microscopy, have a lower number of nerve fibers in the cornea than controls. ${ }^{8}$

\section{Mechanism behind the association between DES and GO}

Although the association is well established, the mechanism to explain the relationship between GO and DES is not completely known. Increased ocular surface exposure due to proptosis and eyelid retraction as well as aqueous tear deficiency appear to be primarily responsible; however, in $\mathrm{GO}$, it is thought that both mechanisms can contribute to dry eye symptoms in patients.

There is evidence to implicate the mechanical impairment of the lids, which is associated with GO as the reason for the symptoms of "evaporative dry eye". In GO, the mechanical impairment is caused by the hypertrophy of extra-orbital muscles, fibrosis of the levator muscle complex, and the increase in orbital fat and connective tissue. ${ }^{28}$ Combined, these factors can lead to increases in the intra-orbital contents, and therefore, an increase in intra-orbital pressure, eye lid retraction, palpebral fissure widening, proptosis, and eventually, the inability to close the lid. ${ }^{28}$ Incomplete blinking results in inadequate tear distribution over the ocular surface, and a widened palpebral fissure permits excess tear evaporation. ${ }^{28}$ One study finds that GO patients' palpebral fissure height correlates with their tear film breakup time. Those with a wider fissure are more likely to have a shorter tear film breakup time, which leads to tear film instability. ${ }^{32}$

Patients with GO have an abnormally high tear film osmolarity, ${ }^{31}$ and this may result from excess evaporation. In mice, tear hyperosmolarity stimulates pro-inflammatory cytokines including interleukin $1 \mathrm{~B}$, tumor necrosis factor $\alpha$, and matrix metalloproteinase $9 .{ }^{33}$ These cytokines activate MAPK cascades, which stimulate further inflammatory cytokines. ${ }^{34}$ This cycle can lead to a high amount of ocular inflammation. Evidence suggests that ocular inflammation mediated by $\mathrm{T}$ lymphocytes is important in the pathogenesis of DES. ${ }^{35}$ Hyperosmolarity may also cause pathological changes to the corneal epithelium cells, where MMP-9 can lyse substrates such as the corneal epithelial basement membrane and tight junction proteins that normally have a corneal epithelial barrier function. ${ }^{36}$ Other changes can include increased desquamation, blunting and loss of microplicae, and cellular swelling. ${ }^{37}$ This epithelial damage then induces more inflammation and apoptosis. These inflammatory cytokines in the tear film lend further evidence to increased exposure and resultant inflammation as a potential cause of DES. ${ }^{38}$

Reduced aqueous tear production also results from the inflammatory process of GO.$^{39}$ Studies indicate that the lacrimal gland might be directly involved in the pathogenesis of dry eye disease. ${ }^{40,41}$ The lacrimal gland also expresses thyroid-stimulating hormone receptors, which makes it a potential target for the autoantibodies in GO. ${ }^{29}$ Therefore, the autoantibodies that bind to lacrimal thyroid-stimulating hormone receptors in $\mathrm{GO}$ patients can cause aberrant signal transduction and potentially contribute to lacrimal gland impairment and resulting aqueous-deficient dry eye. ${ }^{29}$

GO patients also have an abnormal proteinaceous composition of their tear fluid, which is consistent with dysfunction in the lacrimal gland. ${ }^{29}$ One study shows that the IgA/ lysosome ratio is increased in $33 \%$ of GO patients but in only $3 \%$ of controls. ${ }^{42}$ Also, in a study of the tear fluid in patients with $\mathrm{GO}, 28 \%$ of them have an abnormal tear film protein 
profile. ${ }^{43}$ Therefore, the autoantibodies present in GO result in lacrimal gland impairment and abnormal tear fluid, which can lead to aqueous-deficient dry eye.

Although the complete explanation for the mechanism through which GO leads to DES is not entirely known, it is most likely that multiple mechanisms are involved and have a synergistic effect. Known mechanisms include tear film dysfunction due to increased evaporation and/or ocular inflammation, aberrant stimulation of lacrimal glands leading to hyposecretion, and other currently unknown mechanisms currently combining to cause the symptoms and signs of DES.

\section{Treatments of GO associated with DES}

GO has many different treatment options including orbital radiotherapy and surgical interventions. ${ }^{9,39}$ Due to a lack of clinical trials, it is difficult to determine if these treatments contribute to the development or progression of DES.

Nevertheless, there is some evidence to suggest that treatment can exacerbate the symptoms of DES. In a study examining the impact of orbital radiotherapy in patients with GO, although stabilization of the disease was achieved in $12 / 17$ patients, chronic DES developed in 6/17 patients. ${ }^{44}$ In two other studies examining orbital radiotherapy, over $90 \%$ of patients had stabilization of their GO, but $10 \%-12 \%$ of patients had resulting chronic dry eye concerns. ${ }^{45,46}$

Surgery to correct GO, such as lid retraction repair, will reduce evaporative tear loss. However, there is a risk that surgery could damage the lacrimal gland, and lead to lacrimal gland dysfunction and the potential for aqueous deficiency. ${ }^{47}$ Although the patient populations are small in many of these retrospective studies, they nevertheless point to a potential issue in that the treatments of GO might be related to the symptoms of dry eye. Further study is necessary to better determine the dry eye consequences of these treatments.

\section{Treatments of GO improving DES}

Both symptomatic and anti-inflammatory treatments should be used to manage dry eye in GO patients. Electrolyte and polymeric solutions are used for tear replacement. ${ }^{48}$ Lubricant therapy, especially overnight for patients with lagophthalmos, is also helpful. ${ }^{48}$ Decreasing the elevated tear osmolarity in these patients is another potential option. A hypotonic solution can be used, but it causes only a brief decrease in osmolarity. ${ }^{49}$ Alternatively, there are solutions that enter epithelial cells and decrease their osmotic difference. This protects these cells from hyperosmotic damage. ${ }^{50}$ Surgical management to repair the dysfunctional eyelid position can also help protect the ocular surface and tear film. ${ }^{48}$
Because inflammation is involved in the pathogenesis of dry eye, anti-inflammatory treatments can bring dry eye relief to patients with GO. Cyclosporine A can inhibit T-cell proliferation and stop apoptosis of ocular surface cells..$^{51,52}$ However, there is conflicting evidence as to the impact of cyclosporine A treatment for DES in GO patients. In one study, after 2 months of topical cyclosporine A treatment, GO patients showed increased Schirmer tests and tear film breakup time, decreased OSDI score, and decreased apoptosis and MMP-9 expression in conjunctiva epithelial cells. ${ }^{36}$ However, conversely, another study did not find cyclosporine A to be advantageous compared to artificial tears in dry eye treatment for $\mathrm{GO}$ patients. ${ }^{53}$ Other topical steroids and tetracyclines are other anti-inflammatory agents sometimes used to treat DES in GO patients. ${ }^{54}$

\section{Conclusion}

The association between GO and DES has long been established in the literature. This paper sought to review the mechanisms through which DES manifests in GO patients. The evidence points to mechanical impairment of the muscles in the orbit and immune-mediated lacrimal gland dysfunction as the causes of the altered tear film that leads to dry eye in GO patients. Ocular inflammation from these problems also contributes to ocular surface damage. Treatment for DES should be carefully considered in the context of GO, as some treatments for GO may contribute to dry eye symptoms. However, there are multiple treatment considerations that can be used to help with DES in these GO patients.

\section{Disclosure}

Dr Sikder is a consultant for Allergan. The other authors have no proprietary or commercial interests in any concept or product discussed in this article.

\section{References}

1. Lemp MA, Baudoin C, Baum J. The definition and classification of dry eye disease: report of the definition and classification subcommittee of the international dry eye workshop (2007). Ocul Surf. 2007;5(2):75-92.

2. Schaumberg DA, Nichols JJ, Papas EB, Tong L, Uchino M, Nichols KK. The international workshop on meibomian gland dysfunction: report of the subcommittee on the epidemiology of, and associated risk factors for, MGD. Invest Ophthalmolol Vis Sci. 2011;52(4):1994-2005.

3. Perry HD, Donnenfeld ED. Dry eye diagnosis and management in 2004. Curr Opin Ophthalmol. 2004;15(4):299-304.

4. Gürdal C, Saraç O, Genç I, Kırımlıoğlu H, Takmaz T, Can I. Ocular surface and dry eye in Graves' disease. Curr Eye Res. 2011;36(1):8-13.

5. Bothun ED, Scheurer RA, Harrison AR, Lee MS. Update on thyroid eye disease and management. Clin Ophthalmol. 2009;3:543-551.

6. Burch HB, Wartofsky L. Graves' ophthalmopathy: current concepts regarding pathogenesis and management. Endocr Rev. 1993;14(6):747-793.

7. Maheshwari R, Weis E. Thyroid associated orbitopathy. Indian $J$ Ophthalmol. 2012;60(2):87-93. 
8. Villani E, Viola F, Sala R, et al. Corneal involvement in Graves' orbitopathy: an in vivo confocal study. Invest Ophthalmol Vis Sci. 2010;51(9): 4574-4578.

9. Bartley GB, Fatourechi V, Kadrmas EF, et al. Clinical features of Graves' ophthalmopathy in an incidence cohort. Am J Ophthalmol. 1996; 121(3):284-290.

10. Bartley GB, Fatourechi V, Kadrmas EF, et al. Long-term follow-up of Graves ophthalmopathy in an incidence cohort. Ophthalmol. 1996; 103(6):958-962.

11. Mizen TR. Thyroid eye disease. Semin Ophthalmol. 2003;18(4):243-247.

12. Bahn RS, Dutton CM, Natt N, Joba W, Spitzweg C, Heufelder AE. Thyrotropin receptor expression in Graves' orbital adipose/connective tissues: potential autoantigen in Graves' ophthalmopathy. J Clin Endocrinol Metab. 1998;83(3):998-1002.

13. Bahn RS, Heufelder AE. Pathogenesis of Graves' ophthalmopathy. N Engl J Med. 1993;329(20):1468-1475.

14. Smith TJ, Hoa N. Immunoglobulins from patients with Graves' disease induce hyaluronan synthesis in their orbital fibroblasts through the self-antigen, insulin-like growth factor-I receptor. J Clin Endocrinol Metab. 2004;89(10):5076-5080.

15. Yeatts RP. Quality of life in patients with Graves ophthalmopathy. Trans Am Ophthalmol Soc. 2005;103:368-411.

16. Moss SE, Klein R, Klein BEK. Prevalence of and risk factors for dry eye syndrome. Arch Ophthalmol. 2000;118(9):1264-1268.

17. Buchholz P, Steeds CS, Stern LS, et al. Utility assessment to measure the impact of dry eye disease. Ocul Surf. 2006;4(3):155-161.

18. Galor A, Feuer W, Lee DJ, et al. Prevalence and risk factors of dry eye syndrome in a United States veterans affairs population. Am J Ophthalmol. 2011;152(3):377e-384e.

19. Kim KW, Han SB, Han ER, et al. Association between depression and dry eye disease in an elderly population. Invest Ophthalmol Vis Sci. 2011;52(11):7954-7958.

20. Lee S-Y, Petznick A, Tong L. Associations of systemic diseases, smoking and contact lens wear with severity of dry eye. Ophthalmic Physiol Opt. 2012;32(6):518-526.

21. Tong L, Saw SM, Lamoureux EL, et al. A questionnaire-based assessment of symptoms associated with tear film dysfunction and lid margin disease in an Asian population. Ophthalmic Epidemiol. 2009;16(1):31-37.

22. Nowak M, Marek B, Kos-Kudła B, Kajdaniuk D, Siemińska L. Tear film profile in patients with active thyroid orbithopathy. Klin Oczna. 2005;107(7-9):479-482.

23. Achtsidis V, Tentolouris N, Theodoropoulou S, et al. Dry eye in Graves ophthalmopathy: correlation with corneal hypoesthesia. Eur J Ophthalmol. 2013;23(4):473-479.

24. Ismailova DS, Fedorov A, Grusha YO. Ocular surface changes in thyroid eye disease. Orbit. 2013;32(2):87-90.

25. Werner SC. Classification of the eye changes of Graves' disease. Am J Ophthalmol. 1969;68(4):646-648.

26. Mourits MP, Prummel MF, Wiersinga WM, Koornneef L. Clinical activity score as a guide in the management of patients with Graves' ophthalmopathy. Clin Endocrinol. 1997;47(1):9-14.

27. Dolman PJ. Evaluating Graves' orbitopathy. Best Pract Res Clin Endocrinol Metab. 2012;26(3):229-248.

28. Iskeleli G, Karakoc Y, Abdula A. Tear film osmolarity in patients with thyroid ophthalmopathy. Jpn J Ophthalmol. 2008;52(4):323-326.

29. Eckstein AK, Finkenrath A, Heiligenhaus A, Renzing-ko K. Dry eye syndrome in thyroid-associated ophthalmopathy: lacrimal expression of TSH receptor suggests involvement of TSHR-specific autoantibodies. Acta Ophthalmol Scand. 2004;82:291-297.

30. Khurana AK, Sunder S, Ahluwalia BK, Malhotra KC. Tear film profile in Graves' ophthalmopathy. Acta Ophthalmol. 1992;70(3):346-349.

31. Gilbard JP, Farris RL. Ocular surface drying and tear film osmolarity in thyroid eye disease. Acta Ophthalmol. 1983;61(1):108-116.

32. Brasil MV, Brasil OFM, Vieira RP, Vaisman M, Amaral Filho OMB. Tear film analysis and its relation with palpebral fissure height and exophthalmos in Graves' ophthalmopathy. Arq Bras Oftalmol. 2005; 68(5):615-618.
33. Luo L, Li D-Q, Doshi A, Farley W, Corrales RM, Pflugfelder SC Experimental dry eye stimulates production of inflammatory cytokines and MMP-9 and activates MAPK signaling pathways on the ocular surface. Invest Ophthalmol Vis Sci. 2004;45(12):4293-4301.

34. Luo L, Li D-Q, Corrales RM, Pflugfelder SC. Hyperosmolar saline is a proinflammatory stress on the mouse ocular surface. Eye Contact Lens. 2005;31(5):186-193.

35. El Annan J, Chauhan SK, Ecoiffier T, Zhang Q, Saban DR, Dana R. Characterization of effector T cells in dry eye disease. Invest Ophthalmol Vis Sci. 2009;50(8):3802-3807.

36. Gürdal C, Genç I, Saraç O, Gönül I, Takmaz T, Can I. Topical cyclosporine in thyroid orbitopathy-related dry eye: clinical findings, conjunctival epithelial apoptosis, and MMP-9 expression. Curr Eye Res. 2010;35(9):771-777.

37. Gilbard JP, Carter JB, Sang DN, Refojo MF, Hanninen LA, Kenyon KR. Morphologic effect of hyperosmolarity on rabbit corneal epithelium. Ophthalmology. 1984;91(10):1205-1212.

38. Gumus K, Cavanagh DH. The role of inflammation and anti-inflammation therapies in keratoconjunctivitis sicca. Clin Ophthalmol. 2009;3: $57-67$.

39. Rocha EM, Mantelli F, Nominato LF, Bonini S. Hormones and dry eye syndrome: an update on what we do and don't know. Curr Opin Ophthalmol. 2013;24(4):348-355.

40. Harris MA, Realini T, Hogg JP, Sivak-Callcott JA. CT dimensions of the lacrimal gland in Graves orbitopathy. Ophthal Plast Reconstr Surg. 2012;28(1):69-72.

41. Moncayo R, Baldissera I, Decristoforo C, Kendler D, Donnemiller E. Evaluation of immunological mechanisms mediating thyroid-associated ophthalmopathy by radionuclide imaging using the somatostatin analog 111In-octreotide. Thyroid. 1997;7(1):21-29.

42. Khalil HA, De Keizer RJ, Bodelier VM, Kijlstra A. Secretory IgA and lysozyme in tears of patients with Graves' ophthalmopathy. Doc Ophthalmol. 1989;72(3-4):329-334.

43. Khalil HA, de Keizer RJ, Kijlstra A. Analysis of tear proteins in Graves' ophthalmopathy by high performance liquid chromatography. Am J Ophthalmol. 1988;106(2):186-190.

44. Kouloulias V, Kouvaris J, Zygogianni A, et al. Efficacy and toxicity of radiotherapy for Graves' ophthalmopathy: the University of Athens experience. Head Neck Oncol. 2013;5(2):12.

45. Prabhu RS, Liebman L, Wojno T, Hayek B, Hall WA, Crocker I. Clinical outcomes of radiotherapy as initial local therapy for Graves' ophthalmopathy and predictors of the need for post-radiotherapy decompressive surgery. Radiat Oncol. 2012;7:95.

46. Matthiesen C, Thompson JS, Thompson D, et al. The efficacy of radiation therapy in the treatment of Graves' orbitopathy. Int J Radiat Oncol Biol Phys. 2012;82(1):117-123.

47. George J, Nancy-brabois CHU, Nancy V, Oftalmologia C, Medicina F. Risk of dry eye after mullerectomy via the posterior conjunctival approach for thyroid-related upper eyelid retraction. Orbit. 2002;33: 19-26.

48. Sokol J, Foulks GN, Haider A, Nunery WR. Ocular surface effects of thyroid disease. Ocul Surf. 2010;8(1):29-39.

49. Holly FJ, Lamberts DW. Effect of nonisotonic solutions on tear film osmolality. Invest Ophthalmol Vis Sci. 1981;20(2):236-245.

50. Corrales RM, Luo L, Chang EY, Pflugfelder SC. Effects of osmoprotectants on hyperosmolar stress in cultured human corneal epithelial cells. Cornea. 2008;27(5):574-579.

51. Pflugfelder SC. Anti-inflammatory therapy of dry eye. Ocul Surf. 2003; $1(1): 31-36$.

52. Foulks GN. Topical cyclosporine for treatment of ocular surface disease. Int Ophthalmol Clin. 2006;46(4):105-122.

53. Altiparmak UE, Acar DE, Ozer PA, et al. Topical cyclosporine A for the dry eye findings of thyroid orbitopathy patients. Eye. 2010;24(6): 1044-1050.

54. Perry HD, Solomon R, Donnenfeld ED, et al. Evaluation of topical cyclosporine for the treatment of dry eye disease. Arch Ophthalmol. 2008;126(8):1046-1050. 


\section{Publish your work in this journal}

Clinical Ophthalmology is an international, peer-reviewed journal covering all subspecialties within ophthalmology. Key topics include: Optometry; Visual science; Pharmacology and drug therapy in eye diseases; Basic Sciences; Primary and Secondary eye care; Patient Safety and Quality of Care Improvements. This journal is indexed on

Submit your manuscript here: http://www.dovepress.com/clinical-ophthalmology-journal
PubMed Central and CAS, and is the official journal of The Society of Clinical Ophthalmology (SCO). The manuscript management system is completely online and includes a very quick and fair peer-review system, which is all easy to use. Visit http://www.dovepress.com/ testimonials.php to read real quotes from published authors. 